\title{
Palaearctic Origin of Leishmania
}

\section{Sara F Kerr}

Biology Department, University of the Incarnate Word, 4301 Broadway, San Antonio, Texas 78209, USA

The hypothesis of a Palaearctic origin of Leishmania in the early Cenozoic, dispersal to the Nearctic in the late Eocene and to the Neotropical in the Pliocene is presented. It is further hypothesized that murid rodents and their immediate ancestors have been important mammalian reservoirs since the origination of Leishmania. Biochemical, molecular, biogeographical, entomological, mammalalogical and ecological support for these hypotheses are reviewed.

Key words: Leishmania mexicana - Leishmania major - Endotrypanum - Sauroleishmania - Sigmodontinae Muridae - Lutzomyia - Phlebotomus - Sergentomyia - coevolution - biogeography

The genus Leishmania is monophyletic according to Thomaz-Soccol et al. (1993), but inference of its origin and evolution is complicated by its disjunct geographic distribution (WHO 1990). The subgenus Viannia is restricted to the Neotropical region, while the subgenus Leishmania occurs in both the New World (Neotropical and southern Nearctic) and the Old World (Palaearctic, African and Oriental). Killick-Kendrick (1985) suggested that $L$. (L.) chagasi, a member of the $L$. (L.) donovani complex (WHO 1990), may have been imported from the Old World into the New World by humans during historic times, a view that has received support from studies by Beverley et al. (1987), Momen et al. (1987), Rioux et al. (1990), Schonian et al. (1996) and Travi et al. (1998). The distribution of the remaining species in the subgenus Leishmania is not as easy to explain, and its understanding is important to the understanding of the geographic origin of the entire genus. Did the genus originate in the Palaearctic as hypothesized by Lysenko (1971) or the Nearctic as hypothesized by Noyes (1998)?

Noyes (1998) presented a hypothesis for the Neotropical origin of the Leishmania/Endotrypanum clade during the Palaeocene, suggesting that sloths (Xenarthra) served as the first vertebrate reservoirs of the clade, that $L$. hertigi diverged from

\footnotetext{
This work received financial support from National Institutes of Health Grant GM55337.

Correspondence address: 328 Fleetwood, San Antonio, Texas 78232, USA. Fax: (210) 829 3153. E-mail: sfkerr@universe.uiwtx.edu Received 6 July 1999

Accepted 22 November 1999
}

Endotrypanum as a result of adaptation to porcupines (Rodentia: Erethizontidae) during the Eocene, and that Leishmania was introduced into the Nearctic in a porcupine host and carried across the Bering Land Bridge to the Palaearctic during the Miocene in an unspecified mammalian reservoir. Noyes (1998) also hypothesized that Sauroleishmania evolved later in the Miocene, either in the Nearctic or Palaearctic, as a result of adaptation to reptiles. For a number of reasons, these hypotheses are unfounded. First, although porcupines did move from the Neotropical to the Nearctic, the fossil record indicates that this did not occur until after the formation of the Panamanian Land Bridge in the late Pliocene (Marshall et al. 1982, Nowak 1991). Second, the porcupines did not move across the Bering Land Bridge. Third, while great weight is given to the importance of adaptation of $L$. hertigi to the porcupine as a mechanism isolating the genus from Endotrypanum, it is not explained why sloths continue to be important reservoirs of Leishmania. Fourth, the hypothesis requires that Leishmania adapted to murid rodents separately in the Neotropical, the Nearctic and the Palaearctic. Fifth, fossil evidence indicates that phlebotomine sand flies (Lewis 1982), the only vectors, and murid rodents (Nowak 1991), the most important zoonotic reservoirs, both originated in the Palaearctic, making it improbable that Leishmania originated in the Neotropical. Noyes (1998) himself acknowledged that his hypothesis of a Neotropical origin of Leishmania is inconsistent with the position of Sauroleishmania external to Leishmania (Lainson \& Shaw 1987) or the classification of New and Old World species of phlebotomine sand flies in separate genera (Williams 1993).

Two additional concepts, not cited by Noyes (1998), but generally reasoned to support a Neotropical origin of Leishmania, may be incorrect. 
Lainson and Shaw (1987) characterized peripylarian development in L. (Viannia) as the primitive character state, but the validity of this concept has been disputed by Anez et al. (1989) and Croan and Ellis (1996). The greater diversity of Leishmania in the New World than the Old World has been given as evidence of a Nearctic origin (Lainson \& Shaw 1987, Croan et al. 1997); this is based on the erroneous assumption that new species appear at a constant rate, and, therefore, a large number of species indicates a long residence time for a taxa (Cox \& Moore 1993). The diversity of New World Leishmania may instead reflect accelerated evolution in the Neotropical due to climate change and isolation of populations due to extreme topographic relief (Vrba 1992).

Biochemical, molecular, biogeographical, entomological, mammalogical and ecological studies support a simpler scenario, consistent with Lysenko's hypothesis (1971) that Leishmania originated in the Palaearctic. Evidence also strongly supports dispersal from the Palaearctic across the Bering Land Bridge to the Nearctic during the Oligocene, dispersal across the Panamanian land bridge during the Pliocene, and very rapid radiation after arrival in the Neotropical (Figure). Furthermore, murid rodents and their ancestors have probably been the most important reservoirs since the origin of the genus.

Biochemical and molecular evidence - Leishmania was subdivided into two subgenera based on the pattern of development in the sand fly gut: Leishmania (suprapylorian) and Viannia (peripylorian) (Lainson \& Shaw 1987), a classification which is supported by numerous biochemical and molecular studies (Kreutzer et al. 1987, Rioux 1990, Thomaz-Soccol et al. 1993, Schonian et al. 1996, Croan et al. 1997, Noyes et al. 1997, Cupolillo et al. 1998). The phylogenetic trees of Thomaz-Soccol et al. (1993), Noyes et al. (1998) and Croan et al. (1997), which indicate that $L$. (Viannia) and Endotrypanum are ancestral to $L$. (Leishmania), are un-rooted; conceivably they could be reversed, with Sauroleishmania and $L$. (Leishmania) at the base and L. (Viannia) and Endotrypanum at the crown, without changing the taxonomic groupings these studies support, distances between species groups, or parsimony. Conclusions about the relative antiquity of these taxa, based on assumptions of constant rates of evolution, may have underestimated the antiquity of Sauroleishmania and L. (Leishmania) and greatly overestimated the antiquity of $L$. (Viannia) and Endotrypanum.

\section{Palaearctic}

Sauroleishmania

L. (L.) major

$\underline{\text { Nearctic }}$

L. (L.) mexicana

Neotropical

L. (Viannia)

Endotrypanum

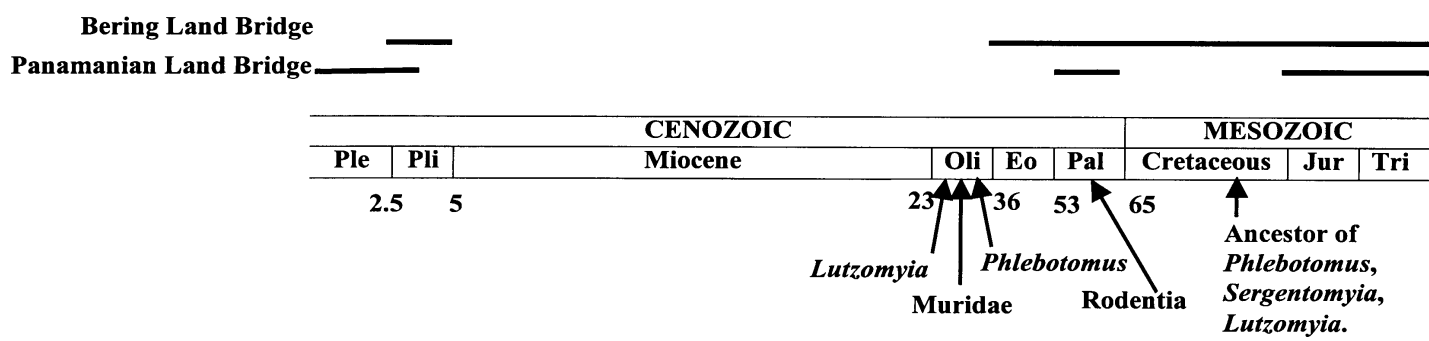

Geological periods showing the approximate dates of the appearance of mammal and insect groups important for the understanding of the evolution of Leishmania. Numbers indicate millions of years before the present. Dates of origination of mammal taxa are from Nowak (1991) and dates of origination of sand flies are from Lewis (1982). The phylogeny of the Sauroleishmania/Leishmania/Endotrypanum clade is based on biogeography, the fossil records of mammals and sand flies, and ecology. Calibration is based on the fossil record and the dates for the existence of the Bering and Panamanian Land Bridges (Kurtén 1972), as illustrated. Zoogeographical regions of origination of each species complex are underlined. 
Molecular evidence of Noyes et al. (1997), including restriction fragment length polymorphisms and sequences of small ribosomal RNA genes, and hybridization studies of kinetoplast DNA, supports the close relationship of L. hertigi and Endotrypanum, as well as the close relationship Leishmania and Sauroleishmania. However, conclusions about the order of evolution are based primarily on an incorrect interpretation of the biogeographical data.

Thomaz-Soccol et al. (1993) presented a cladogram including New and Old World species of Leishmania, which retained the two main branches, Viannia and Leishmania. Leishmania hertigi was placed in the Leishmania subgenus based on suprapylorian development in the sand fly, but it was determined that an equally parsimonious tree could place it in the subgenus Viannia. They hypothesized that Leishmania originated in the Mesozoic prior to the separation of Gondwana, with division of $L$. (Leishmania) and L. (Viannia) occurring after the separation of Africa and South America. They suggested that New World species of L. (Leishmania) might have become separated from Old World species in the early Cenozoic, by the movement from East to West of rodent reservoirs such as ancestors of Caviomorphs. The phylogeny of Leishmania was inferred from a comparison of DNA and RNA gene sequences (Croan \& Ellis 1996, Croan et al.1997); results supported grouping species into complexes as presented by the World Health Organization (1990), but indicated Sauroleishmania should be included within the genus. They developed a phylogenetic tree, based on an algorithm with an assumed molecular clock, that placed L. herreri and Endotrypanum at the base of the tree, followed by the L. hertigi complex, Sauroleishmania, L. (Viannia) and L. (Leishmania). Their placement of L. herreri and $L$. hertigi at the base of the tree contradicts the idea that peripylarian development is a primitive evolutionary characteristic. Croan et al. (1997) suggested that the greater diversity of Leishmania in the New World than the Old World is evidence of origination in the New World.

Fernandes et al. (1993) estimated divergence rates for Leishmania based on metazoans, for which fossil evidence of divergence times were available, assuming that the rate was the same for kinetoplasts. They estimated that New and Old World Leishmania diverged 90 million years ago, when South America and Africa separated. This approach fails to consider that divergence rates may occasionally speed up due to factors such as climate change and vicariance of populations. Because of this, a lineage that evolved rapidly due to changing environmental conditions and isolation might be assumed to be much older than it actually is.
Molecular support for the placement of $L$. (Viannia) at the crown of a tree of the Leishmanial Endotrypanum clade may be found in a study by McMahon-Pratt et al. (1992), which concluded that the absence of the GP46/M-2 gene in the subgenus $L$. (Viannia), in contrast to its presence in $L$. (Leishmania), Sauroleishmania tarentolae and Crithidia fasciculata, may be related to peripylarian development of the promastigote in the sand fly gut. McMahon-Pratt et al. (1992) concluded that the most parsimonious explanation is that a loss of the GP46A gene family occurred following separation of the L. braziliensis complex, prior to speciation within the complex. Alternatively, they suggested GP46/M-2 has undergone rapid evolution in the L. braziliensis complex. Either of these explanations is consistent with the placement of $L$. (Viannia) at the crown of a phylogenetic tree of Leishmania.

Biogeographical evidence - The earth experienced a period of net cooling and drying 2.5-1.5 million years ago; grassland biomes required by the earliest murid rodents shifted towards the equator, and tropical forest biomes receded (Vrba 1992). Along with their required biome, the distribution of sigmodontine rodents (Rodentia: Muridae: Sigmodontinae) moved across the Panamanian land bridge into South America. A warming trend followed 900-600 thousand years ago, when tropical forests expanded and grassland islands were isolated at high elevations. Climate change, combined with the extreme topographic diversity of Central and South America, resulted in vicariance of the sigmodontine rodents and a greatly accelerated rate of speciation. It is not far-fetched to speculate that both Leishmania and their vectors, Lutzomyia, which were closely associated with the rodents, underwent similarly accelerated radiations, resulting in the present high species diversity in the Neotropical.

Entomological evidence - The close evolutionary fit between species of Leishmania and their sand fly vectors, presumably due to coevolution, was demonstrated by Killick-Kendrick (1985); the stronger restriction of vectors of dermotrophic species of Leishmania than vectors of either the visceralizing donovani/infantum group (KillickKendrick 1985) or L. (Viannia) (Lainson \& Shaw 1987) supports the hypothesis that dermotrophic species evolved first. The vector of Sauroleishmania is Sergentomyia, which is restricted to the Old World (Lane 1993). Two genera of phlebotomine sand flies are vectors for Leishmania among mammals: Phlebotomus in the Old World and Lutzomyia in the New World. Entomologists such as Lewis (1982) and Williams (1993) assumed that these genera evolved in iso- 
lation for 120 million years; more likely, the separation occurred less than 36 million years ago, during the Oligocene. The fossil record indicates that a phlebotomine sand fly, ancestral to Phlebotomus, Sergentomyia, and Lutzomyia, existed 120 million year ago in what is now Lebanon; Phlebotomus from 30 million years ago was preserved in Baltic amber; and Lutzomyia from 26 million years ago was preserved in Mexican amber (Lewis 1982). In summary, evidence indicates that the phlebotomine ancestor of Sergentomyia and Phlebotomus evolved in the Palaearctic Region during the Cretaceous; Phlebotomus evolved in the Palaearctic by the late Eocene, and Lutzomyia diverged from Phlebotomus during the Oligocene after the break in the Bering land bridge. The classification of phlebotomine sand flies by Williams (1993) is consistent with this interpretation.

Mammalogical evidence - Although Leishmania species are much more specialized physiologically for sand fly vectors than mammalian hosts, ecological factors have limited the number of mammalian species fulfilling WHO (1990) criteria for the implication of reservoirs. For example, the much higher prevalence of $L$. mexicana in Neotoma micropus than in other mammals is attributable to the fact that its burrows provide favorable habitat for the vector, $L u$. anthophora (Kerr et al. 1995). In addition, because infected mammals may live for several years, while infected vectors live only a few weeks, the mammals play a very important role in the persistence of infection in an area, and introduction into new localities (Kerr et al. 1997). Most reservoirs of zoonotic cutaneous leishmaniasis, in both the Old World and the New World, are murid rodents. Old World reservoirs include members of the subfamily Gerbillinae: Rhombomys opimus in central Asia (Kozevnikov 1963) and Iran (Nadim \& Faghigh 1968), and Psammomys obesus and Meriones crassus in Israel (Schlein et al. 1984). Nearctic reservoirs of zoonotic cutaneous leishmaniasis belong to the subfamily Sigmodontinae: N. micropus (Kerr et al. 1995, McHugh et al. 1990) and N. albigula in the USA (Kerr et al. 1999) and Ototylomys phyllotis and Nyctomys sumichrasti in Belize (Lainson \& Strangways-Dixon 1964). Murid rodents originated in the Palaearctic in the Oligocene and dispersed across the Bering Land Bridge to the Nearctic. New World Rats and Mice (Rodentia: Muridae: Sigmodontinae) evolved in the Nearctic region, dispersed across the Panamanian Land Bridge to the Neotropical during the Pliocene, then underwent very rapid radiation (Eisenberg 1989, Vrba 1992). According to Vrba (1992) South American cricetids (= sigmodontines) multiplied to about 40 genera and more than 200 species within approximately 2.5 million years. Studies by Wirth and McMahon-Pratt (1982) demonstrate a similarly rapid rate of evolution in New World Leishmania.

Ecological evidence - The ecological similarity of the USA population of Leishmania mexicana to L. major suggests that they may be closely related. The reservoirs of both are burrowing rodents that inhabit grasslands. Oddly, the ecology of $L$. mexicana in the USA is more similar to the ecology of L. major in central Asia than it is to the ecology of conspecifics in Mexico and Central America, where the rodent burrow nidus is replaced by a forest cycle. This is attributable to the fact that more humid conditions, with warm weather throughout the year, have released sand flies to occupy the forest canopy, rather than be confined to burrows. This could have led to arboreal mammals, including murid rats, echimyid rats and porcupines (Rodentia), sloths (Xenartha), and opossums (Marsupialia), replacing burrowing mammals as hosts for Leishmania in the Neotropics.

Conclusion - The following scenario for the evolution of Leishmania is proposed. Sauroleishmania originated in Cretaceous reptiles in the Palaearctic region. The earth cooled, reptiles declined, and during the Cenozoic, mammals radiated. A phlebotomine species ancestral to Phlebotomus and Lutzomyia adapted to feeding on rodents rather than reptiles; rodent burrows provided high humidity and shelter from cold for both rodents and sand flies. Leishmania, along with its phlebotomine vector and a rodent reservoir, could have evolved in the Palaearctic and dispersed to the Nearctic at the end of the Eocene, at which time the land bridge between the Palaearctic and Nearctic was intact, and the climate was sufficiently warm to allow the dispersal of sand flies (Kurtén 1972). The fossil record of sand flies, scanty though it may be, provides a calibration point for the separation of Phlebotomus and Lutzomyia during the Oligocene, coinciding with a break in the land connection of the Palaearctic with the Nearctic, a continued cooling trend, and the radiation of murid rodents in both the Palaearctic and Nearctic regions.

After the formation of the Panamanian Land Bridge 3 million years ago, the radiation of sigmodontine rodents, Leishmania and Lutzomyia accelerated rapidly. When the climate reverted to warm and humid, sand flies may have been released from confinement to burrows and inhabited the forest canopy. A variety of arboreal mammals may then have replaced burrowing animals as hosts for Leishmania. Mammals of South American origin, such as echimyid rodents, porcupines, sloths, and opossums, lacking prior exposure, may have 
been particularly susceptible. Operating in concert with climatic change and vicariance, adaptation to new mammalian hosts might have greatly accelerated the rate of speciation of Leishmania.

\section{ACKNOWLEDGEMENTS}

To CP McHugh, R Merkelz, JT Sullivan and B McCormick, who provided valuable critical comments.

\section{REFERENCES}

Anez N, Nieves E, Cazorla D 1989. The validity of the developmental pattern in the sandfly gut for classification of Leishmania. Trans $R$ Soc Trop Med Hyg 83: 634-635.

Beverley SM, Ismach RB, McMahon Pratt D 1987. Evolution of the genus Leishmania as revealed by comparisons of nuclear DNA restriction fragment patterns. Proc Natl Acad Sci Evol Med Sci 84: 484-488.

Cox CB, Moore PD 1993. Biogeography an Ecological and Evolutionary Approach, Blackwell Scientific Publications, London, $x+326$ pp.

Croan D, Ellis J 1996. Phylogenetic relationships between Leishmania, Viannia and Sauroleishmania inferred from comparison of a variable domain within the RNA polymerase II largest subunit gene. Mol Biochem Parasitol 79: 97-102.

Croan DG, Morrison DA, Ellis JT 1997. Evolution of the genus Leishmania revealed by comparison of DNA and RNA polymerase gene sequences. $\mathrm{Mol}$ Biochem Parasitol 89: 149-159.

Cupolillo E, Momen H, Grimaldi Jr G 1998. Genetic diversity in natural populations of New World Leishmania. Mem Inst Oswaldo Cruz 93: 663-668.

Eisenberg JF 1989. Mammals of the Neotropics. The Northern Neotropics. Vol. I. Panama, Colombia, Venezuela, Guyana, Suriname, French Guiana, The University of Chicago Press, Chicago, USA, $x+449$ pp.

Fernandes AP, Nelson K, Beverley SM 1993. Evolution of nuclear ribosomal RNAs in kinetoplastid protozoa: perspectives on the age and origins of parasitism. Proc Natl Acad Sci Evol 90: 11608-11612.

Kerr SF, McHugh CP, Dronen NO 1995. Leishmaniasis in Texas: prevalence and seasonal transmission of Leishmania mexicana in Neotoma micropus. Am J Trop Med Hyg 53: 73-77.

Kerr SF, Grant WE, Dronen Jr. NO 1997. A simulation model of the infection cycle of Leishmania mexicana in Neotoma micropus. Ecological Modeling 98: 187198.

Kerr SF, McHugh CP, Merkelz R . 1999. A focus of Leishmania mexicana near Tucson, Arizona. Am J Trop Med Hyg 61: 378-379.

Killick-Kendrick R 1985. Some epidemiological consequences of the evolutionary fit between leishmaniae and their phlebotomine vectors. Bull Soc Path Ex 78: 747-755.

Kozevnikov PV 1963. Two nosological forms of cutaneous leishmaniasis. Am J Trop Med Hyg 12: 719724.

Kreutzer RD, N Souraty, ME Semko 1987. Biochemical identities and differences among Leishmania species and subspecies. Am J Trop Med Hyg 36: 22-32.
Kurtén B 1972. The Age of Mammals, The Trinity Press, Worcester, London, $250 \mathrm{pp}$.

Lainson R, Shaw JJ 1987. Evolution, classification and geographical distribution. In W Peters \& R KillickKendrick (eds), The Leishmaniases in Biology and Medicine, Academic Press, London, p. 1-120.

Lainson R, Strangways-Dixon J 1964. The epidemiology of dermal leishmaniasis in British Honduras: part II. Reservoir-hosts of Leishmania mexicana among the forest rodents. Trans R Soc Trop Med Hyg 58: 136-153.

Lane RP 1993. Sandflies (Phlebotominae). In RP Lane \& RW Crosskey (eds), Medical Insects and Arachnids, Chapman \& Hall, London, p. 78-119.

Lewis DJ 1982. A taxonomic review of the genus Phlebotomus (Diptera: Psychodidae). Bull Brit Mus (Nat Hist) Entomology Series 45: 121-203.

Lysenko AJ 1971. Distribution of leishmaniasis in the Old World. Bull WHO 44: 515-520.

Marshall LG, Webb SD, Sepkoski Jr JJ, Raup DM 1982. Mammalian evolution and the great American interchange. Science 215: 1351-1357.

McHugh CP, Grogl M, Kerr SF 1990. Isolation of Leishmania mexicana from Neotoma micropus collected in Texas. J Parasitol 76: 741-742.

McMahon-Pratt D, Traub-Cseko Y, Lohman KL, Rogers DD, Beverley SM 1992. Loss of the GP46/M-2 surface membrane glycoprotein gene family in the Leishmania braziliensis family. Mol Biochem Parasitol 50: 151-160.

Momen H, Grimaldi Junior G, Dean LM 1987. Leishmania infantum, the aetiological agent of American visceral leishmaniasis (AVL)? Mem Inst Oswaldo Cruz 82: 447-448.

Nadim A, M Faghigh 1968. The epidemiology of cutaneous leishmaniasis in the Isfahan Province of Iran I. The reservoir II. The human disease. Trans $R$ Soc Trop Med Hyg 61: 543-549.

Nowak RM 1991. Walker's Mammals of the World, 5th ed., Vol. II, The Johns Hopkins University Press, Baltimore and London, p. 643-1629.

Noyes H 1998. Implications of a Neotropical origin of the genus Leishmania. Mem Inst Oswaldo Cruz 93: 657-661.

Noyes HA, Arana BA, Chance ML, Maingon R 1997. The Leishmania hertigi (Kinetoplastida; Trypanosomatidae) complex and the lizard Leishmania: their classification and evidence for a Neotropical origin of the Leishmania-Endotrypanum clade. J Euk Microbiol 44: 511-517.

Rioux JA 1990. Taxonomy of Leishmania. Use of isoenzymes. Suggestions for a new classification. Ann Parasitol Hum Comp 65: 11-125.

Schlein Y, A Warburg, LF Schnur, SM LeBlancq, AE Gunders 1984. Leishmaniasis in Israel: reservoir hosts, sandfly vectors and leishmanial strains in the Negev, Central Arava and along the Dead Sea. Trans R Soc Trop Med Hyg 78: 480-484.

Schonian G, Schweynoch C, K Zlateva, L Oskam, N Kroon, Y Graser, W Presber 1996. Identification and determination of the relationships of species and strains within the genus Leishmania using single 
primers in the polymerase chain reaction. Mol Bioch Parasitol 77: 19-29.

Thomaz-Soccol V, Lanotte G, Rioux JA, Pratlong F, Martini-Dumas A, Serres E 1993. Monophyletic origin of the genus Leishmania Ross, 19031993. Ann Parasitol Hum Comp 68: 107-108.

Travi, BL, Osorio Y, Becerra MT, Adler GH. 1998. Dynamics of Leishmania chagasi infection in small mammals of the undisturbed and degraded tropical forests of northern Colombia. Trans R Soc Trop Med Hyg 92: 275-278.
Vrba ES 1992. Mammals as a key to evolutionary theory. J Mammal 73: 1-28.

WHO-World Health Organization 1990. The Leishmaniases, Technical Report Series 701, Geneva, Switzerland, $140 \mathrm{pp}$.

Williams P 1993. Relationships of phlebotomine sand flies (Diptera). Mem Inst Oswald Cruz 88: 177-183.

Wirth DF, McMahon-Pratt D 1982. Rapid identification of Leishmania species by specific hybridization of kinetoplast DNA in cutaneous lesions. Proc Nat Acad Sci 79: 6999-7003. 